\title{
Teachers' Level of Adaptability and Performance: Their Response to the Rapidly Transforming Academic World
}

\author{
Leslie M. Andres ${ }^{1}$, Jacqueline B. Dela $\mathrm{Cruz}^{2}$, Mila P. Gonzaga ${ }^{3}$, Irene S. Rodriguez ${ }^{4}$, \\ Julie A. Sanchez ${ }^{5}$, Arjay F. Ortiz
}

\author{
${ }^{1}$ Faculty, Triala National Highschool, Guimba, Nueva Ecija, Philippines \\ ${ }^{3}$ Faculty, Juan R. Liwag Memorial High School, Gapan City, Nueva Ecija, Philippines \\ ${ }^{2,4,5}$ Faculty, NEUST-SAOC, San Antonio, Nueva Ecija, Philippines \\ ${ }^{6}$ Faculty, Business Administration Department, NEUST, Philippines
}

Received: 03 Apr 2021; Received in revised form: 19 May 2021; Accepted: 03 Jun 2021; Available online: 17 Jun 2021 (C)2021 The Author(s). Published by Infogain Publication. This is an open access article under the CC BY license (https://creativecommons.org/licenses/by/4.0/).

\begin{abstract}
This research investigated the level of adaptability and performance of junior and senior high school teachers in Guimba, Nueva Ecija as their response to the rapidly transforming academic world. It utilized descriptive-correlational research and researchers-made instrument. The researchers discovered that the responders are on average 37 years old. They were usually master's degree holders who were single. The majority of them focused on Science and Mathematics as their areas of specialization. The bulk of them dealt with one to five distinct disciplines depending on the number of courses they taught. They have six to seven teaching loads at any given time. In terms of their other related work, the majority of them have two other associated works. Teachers have very satisfactory teaching performance and a high level of adaptability in completing other related jobs and adapting to a fast-changing academic environment. Lastly, teachers with a high level of adaptation also have a high level of teaching performance.
\end{abstract}

Keywords-Level of adaptability, multitasking, performance, rapid change, teachers.

\section{INTRODUCTION}

Teachers of an earlier generation are fronting to a diverse academic world of this generation, where, teaching, learning, paperwork, and communications are greatly evolving to a technologically influenced setting. Addressing the quick revolution of a digital age culture has challenged every educator. "It has come to the system of the whole administration that stakeholders of quality education have fairly different styles of learning as influenced by the social media"[18].For the teachers, who have just come to the early stage of the culture, reveals a quite annoying job. But, their heart should not just stop on receiving a long-been-promised raise of salary, but, immerse themselves at the deepest motive of being a teacher. "Go with the flow, grow with a plow and glow with a blow". But how may this be? That is where this study originated its concept. One could be intelligent enough to disseminate information to school children but, to effectively pick it up, is a real challenge. This is based on theories of "Choking Under Pressure" [5] where two groups that "can explain the choking under pressure phenomenon: attentional theories and drive theories"[4].Beilock\& Gray, [9], says that"attentional theories describe how pressure changes the attentional mechanisms and memory structures supporting performance. Most strategies that have been proposed to alleviate choking in sports are derived from these attentional theories and focus on adapting individuals to the types of attentional monitoring that are thought to be prompted by pressure situations. It simply means that a mountain of tasks and responsibilities on a limited time and earnings". "No overtime pay, no hazard pay, yet, still stands to be a "teacher" anywhere, anytime. "It is 
remarkable indeed, that, studies show that while arousal increases, performance is enhanced but only up to a certain threshold (Easterbrook, 1959; Humphreys \&Revelle, 1984; cf. Hanin, 1995)". "Beyond this threshold, performance will suffer"'[13].

Multitasking, on the other hand, is a special skill, a gift it may be, but for how far it may be healthy having this? As The Stanford researchers compared groups of people based on their tendency to multitask and their belief that it helps their performance "found that heavy multitaskers-those who multitask a lot and feel that it boosts their performance-were actually worse at multitasking than those who like to do a single thing at a time".Moreover, Matt D'Angelo, Staff, February 6, 2019 [15] stated that"Multitasking means constantly switching between tasks, and sometimes that can destroy productivity. Heavy multitaskers were less mentally organized, struggled at switching from one task to another, and had a hard time differentiating relevant from irrelevant details". "Many people though, believe multitasking is focusing on more than one task at a time, which is actually impossible" [19], says Andy Kerns. "He believed that what is really happening is only shifting attention from one thing to the next - music to email to chat alerts - every few seconds, without ever being fully present on one task. He added, that in most relevant cases, like in a workplace, it is possible to multitask in some scenarios without hindering your overall desired output". Kendra Cherry, June 24, 2019 [14], once said that "multitasking seems like a great way to get a lot done at once". "But, some researchers suggest that multitasking can actually reduce productivity by as much as $40 \%$ ! It actually kills productivity. By bare eyes, it looks like getting multiple things done at the same time, but it is only being done quickly shifting attention and focus from one thing to the next. Switching from one task to another makes it difficult to tune out distractions and can cause mental blocks that can slow you down,"Kendra Cherry, June 24, 2019, reiterated. In the past, many people believed that multitasking was a good way to increase productivity. After all, whenever working on several different tasks at once, is bound to accomplish more. Recent research, however, "has demonstrated that switching from one task to the next takes a serious toll on productivity"[6] [7] [8]."Multitaskers have more trouble tuning out distractions than people who focus on one task at a time. Also, doing so many different things at once can actually impair cognitive ability" [1].

Thus, this study finds meaning and substance. It aimed to examine the relationship between the teacher's level of adaptability and their multitasking performance. Specifically, this sought to describe the profile, level of adaptability, and performance of junior and senior high school teachers and examine the relationships that exist between and among these variables.

\section{METHODOLOGY}

"This study utilized descriptive-correlational research design"[10], [20]. "This design is used to obtain information concerning the current status of the phenomena to describe what exists with respect to variables or conditions in a situation"[12]. Additionally, correlational research design aims to investigate the extent to which variations in one factor corresponds with variations in one or more other factors in the population of interest. This study was conducted in Triala, Guimba, Nueva Ecija at Triala National High School. 38 Junior and Senior High School teachers were respondents of this study and were picked using total enumeration sampling. The research instrument used in this study was a researchers-made questionnaire. A pre-test was done on 15 teachers who were not participants in this study. The result of the pre-test was tallied and experts in the field of Statistics and Mathematics were asked to validate and test the reliability of the questionnaire using Cronbach's Alpha. The result revealed the computed value of 0.89 or $89 \%$ which proved that the questionnaire was valid and reliable.Moreover, ethical steps were considered in data gathering. As such, the first step was to secure a letter of approval for the School Principal and the teachers to conduct the gathering of data. The researchers personally administered, explained, and retrieved the questionnaires to secure the confidentiality, validity, and reliability of the results. The data gathered were tallied, tabulated, and analyzed according to the problems of the study. In describing the profiles of the respondents, the frequency counts and percentage distribution were used as the main statistical tools. To describe the level of adaptability of the respondents, a weighted mean was employed. Additionally, to describe the level of teaching performance of the respondents, mean or average was utilized. The following interpretation below was used for the respondent's level of adaptability with its corresponding weighted means:

\begin{tabular}{|c|c|c|}
\hline Range & $\begin{array}{c}\text { Verbal } \\
\text { Description }\end{array}$ & Indication \\
\hline $3.26-4.00$ & Strongly Agree & Very High \\
\hline $2.51-3.25$ & Agree & High \\
\hline $1.76-2.50$ & Disagree & Low \\
\hline $1.00-1.75$ & $\begin{array}{l}\text { Strongly } \\
\text { Disagree }\end{array}$ & Very Low \\
\hline
\end{tabular}


The teaching performance of the respondents was described using the following arbitrary numerical guide.

\begin{tabular}{|c|c|}
\hline $\begin{array}{l}\text { Descriptive } \\
\text { Equivalent }\end{array}$ & Grade Scale \\
\hline $4.500-5.000$ & Outstanding \\
\hline $3.500-4.499$ & Very Satisfactory \\
\hline $2.500-3.499$ & Satisfactory \\
\hline $1.500-2.499$ & Unsatisfactory \\
\hline below 1.499 & Poor \\
\hline
\end{tabular}

To investigate whether the profiles of the respondents were related to their teaching performance, and respondents' level of adaptability to their teaching performance, Pearson product-moment correlation and Spearman's rho were used.

\section{RESULTS AND DISCUSSION}

\section{Profile of the Respondents}

The respondents have a mean age of 37 , where the highest group belong to the youngest bracket age of 20-30 years old, that typically followed Singles, as they were the youngest. And made a turnaround result when Number of years are being asked - elders have more of the number of years in service than of the younger generation, but still, the largest number of new teachers overpowered the older ones. While twenty-seven (27) or $71.05 \%$, invest for a Master's Degree, least is on doctor's degree, it does not necessarily mean that the respondents will stop studying. In an interview, almost Twenty-five,(25) plan to pursue a doctor's degree. As to the area of Specialization of the teacher-respondents, it shows a relatively balanced number for every subject where, Filipino and English have number, six (6) or $15.79 \%$, Science with seven (7), $18.43 \%$, Eight (8) Mathematics on $21.05 \%$, two (2) on AralingPanlipunan, (5.26\%). MAPEH teacher numbered three (3) or $7.89 \%$, ESP with two (2) or $5.26 \%$, and the last, TLE with four (4) or $10.53 \%$. In their Number of Subjects taught, twenty (20) or $52.63 \%$ of the total population teach one subject. Eleven (11) or $28.94 \%$ teach two (2) different subjects, $5.26 \%$ (2) teach three different subjects, five (5) among thirty-eight teacher-respondents teach four different subjects and nobody teaches five different subjects. Moreover, the Number of Teaching loads where the largest teaching loads fall on six (6) loads which reveals $52.64 \%$ of the population. The next highest is thirteen (13) teacher-respondents who have five loads $(34.21 \%)$, and the least have seven and above loads which are $13.15 \%$.In terms of their other Related Work results has revealed that thirty-five (35) teacher-respondents or $92.11 \%$ have zero to two (0-2) and three to five (3-5) or
7.89\%. However, no teacher-respondent has six and above loads.

\section{Level of Adaptability of the Respondents}

Results revealed the level of adaptability of the teachers. Where it is divided into sub-components: performing other related work and responding to the rapidly transforming academic world.

\subsection{Performing Other Related Work}

Results disclosed that the highest weighted mean (WM) was obtained by the statement "I shoulder school and office, cleaning supplies that the school does not provide", which was answered by the teacher-respondents as Strongly Agree" and interpreted as Very High". The teacher-respondents also answered "Strongly Agree" on the statements, "I am sensitive to student's need", "I do paperwork while doing test questions", "I take the additional cost for my internet services, printers, bond papers, electric bills, etc.", which are indicated by weighted means (WM) of 3.57, 3.52, and 3.56 respectively and all interpreted as "Very High". The lowest WM (2.85) was given to the statement "I finish work first before family time", answered as "Agree" and described as "High". The average weighted mean of 3.36 and interpreted as "Very High" proved that, in general, teacherrespondents high-level adaptability or can still do other related tasks if asked for by the nature of work. The results indicate that the teacher-respondents can still be trustworthy of doing a great job while adding more and more tasks aside from a boxed job description of responsibility. The most powerful is the decision to take the additional cost to make their output on students at its best while the weakest is giving up the time for their family or loved ones.

\subsection{Responding to Rapidly Transforming Academic World}

Results revealed that teacher-respondents answered "Strongly Agree" on the statement "I let my students utilize technology while they learn." which was given by a WM of 3.80, described as "Very High" and covered the highest spot. Additionally, teacher-respondents also answered "Strongly Agree" and interpreted as "Very High" on the statements "Gadgets like smartphones, tablets and laptops help me to perform my task faster and easier with WM 3.57, and "I can do my task independently on my laptop (Word, Excel, PPT, Publisher, etc.)" and, "I can easily integrate new trends in my lessons" with WMs of $3.57,3.35$, and 3.45 respectively. The lowest spot was given to the statement "Technology requires me to think differently about professional development." with WM of 2.96, answered as "Agree" and interpreted as "High". The average weighted mean of $\mathbf{3 . 3 1}$ which interpreted as "Very 
High" demonstrates that teacher-respondents, in general, have a high level of Adaptability as they respond to a rapidly transforming academic World. The results further proved that teacher-respondents, though on a faster transition of students that requires different teaching styles, can still be worthy to teach and while they adapt to transforming the academic world.

\section{Teaching Performance Level of the Respondents}

Results disclosed that twenty-four (24) among thirty-eight (38) teacher-respondents $(63.16 \%)$, have verbally described being "Very Satisfactory", which rated on a bracket from 3.50 to 4.49 . Fourteen (14) or $36.84 \%$ of

Table 1: Relationship between Respondent's Profile and Teaching Performance them fall on a bracket of "Outstanding" with grades from 4.50 - 5.00. However, grade brackets 2.5-3.49, 1.50- 2.49, and below 1.49 that lie on Verbal Description of Satisfactory, Unsatisfactory and Poor got zero which means, nobody among those teacher-respondents got those low scores. In general, a mean of 4.37 reveals a Very Satisfactory Verbal Description that pertains to a very satisfying performance of the teachers as they respond to the needs of students within or out of the workplace.

\section{Relationship between Respondent's Profile and Teaching Performance}

\begin{tabular}{|c|c|c|}
\hline Profile & & TeachingPerformance \\
\hline \multirow{2}{*}{ Gender } & $\mathrm{R}$ & .032 \\
\hline & p-value & .526 \\
\hline \multirow{2}{*}{ Civil Status } & $\mathrm{R}$ & .026 \\
\hline & p-value & .486 \\
\hline \multirow{2}{*}{ Number of years in service } & $\mathrm{R}$ & $-.106^{* *}$ \\
\hline & $\mathrm{p}$-value & .004 \\
\hline \multirow{2}{*}{ Educational Attainment } & $\mathrm{R}$ & $.085^{* *}$ \\
\hline & $\mathrm{p}$-value & .000 \\
\hline \multirow{2}{*}{ Area of Specialization } & $\mathrm{R}$ & .032 \\
\hline & p-value & .526 \\
\hline \multirow{2}{*}{ Number of Subject Taught } & $\mathrm{R}$ & $-.342^{* *}$ \\
\hline & p-value & .000 \\
\hline \multirow{2}{*}{ Number of Teaching Loads } & $\mathrm{R}$ & $-.300^{* *}$ \\
\hline & p-value & .000 \\
\hline \multirow[t]{2}{*}{$\begin{array}{c}\text { Number of Other Related } \\
\text { Works }\end{array}$} & $\mathrm{R}$ & $-.351^{* *}$ \\
\hline & $\mathrm{p}$-value & .000 \\
\hline
\end{tabular}

*. Correlation is significant at the 0.05 level (2-tailed).

**. Correlation is significant at the 0.01 level (2-tailed).

Gender and civil status are not significantly related to the respondents' teaching performance with the computed rvalue of 0.032 and p-value of 0.526 which is higher than the alpha value 0.01 and 0.026 and p-value 0.486 , higher than the alpha value 0.01 ., respectively. The results revealed that gender and civil status do not affect their teaching performance. On the other hand, a number of years in service revealed a negatively highly significant with a $-.106 \mathrm{r}$ and $\mathrm{p}=$ value of 0.004 . which depicts the higher the number of years in service, the lower the teaching performance. In this connection, a study states that teachers' teaching experience is very vital in promoting higher academic performance. The effect of teachers' experience on pupils' learning found a positive relationship between teachers' effectiveness and their years of experience, but not always as significant or an entirely linear one [16]. Owolabi (2007, Abraham and Morrison (2006), and Darling Hammond (2000) [17] also agree that teachers' years of experience as a measure of quality is important in the achievement of students' academic 
performance. Moreover, educational attainment disclosed positively highly significant that pushes to reject the hypothesis. This means that the higher the educational attainment, the higher the teaching performance. This is shown in the r-value of .085 and p-value of .000 that says, the null hypothesis should be rejected. Looking at the results on "Area of specialization", it displays an rvalue and p-value of .032 and .526 respectively that could be interpreted that even when a teacher teaches a subject that he specializes in or not, his level of performance remains the same. It drives to accept the null hypothesis. But, the teacher shall have a deeper understanding of their content area through increased repetition in teaching that material and more targeted and in-depth professional development [3]. Under "Subject taught", the r-value of -.342 and pvalue of .000 depicts a negatively highly significant effect on teaching performance which means the higher the number of subjects taught, the lower the teaching performance. By teaching a smaller number of subject areas, teachers should be able to plan for and use their instructional time more efficiently and have more time for professional development and collaboration with colleagues[11]. This shall reject the null hypothesis.

Having almost the same values, the number of teaching loads is negatively highly significant which drives to reject the null hypothesis, with an r-valueof .-300 and p-value of .000 . This fervently means that the higher the number of teaching loads, the lower the teaching performance. Performing other related tasks reveals a negatively highly significant effect that clearly proves by the r-value of -.351 and p-value of .000 . It demands to reject the null hypothesis. For when the higher the other related work, the teaching performance lowers. As Andrew Yap, on January 15, 2015, says, "Excessive stress leads to mental exhaustion and poor health, but not enough stress results in boredom and demotivation" [2].

5. Relationship Between Teacher-respondents Level of Adaptability and their Teaching Performance

Table 2: Relationship Between Teacher-respondents Level of Adaptability and their Teaching Performance

\begin{tabular}{|c|c|c|}
\hline Level of Adaptability & & Teaching Performance \\
\hline \multirow{2}{*}{ Performing Other Related Works } & $\mathrm{R}$ & $.270^{* *}$ \\
\hline & p-value & .000 \\
\hline \multirow{2}{*}{$\begin{array}{l}\text { Responding to the Rapidly Transforming Academic } \\
\text { World }\end{array}$} & $\mathrm{R}$ & $.295^{* *}$ \\
\hline & $\mathrm{p}$-value & .000 \\
\hline
\end{tabular}

\footnotetext{
*. Correlation is significant at the 0.05 level (2-tailed).

**. Correlation is significant at the 0.01 level (2-tailed).
}

Performing other related tasks has a highly positive significant relationship to teaching performance. This is indicated with the computed $r$ value 0.270 and $p$-value 0.000 which is lower than the alpha value 0.01 . It says that the higher the level of adaptability, the higher the teaching performance. It could be gleaned that the hypothesis which stated that "There is no significant relationship between teacher respondents' level of adaptability and their teaching performance" is rejected. In the same vein, however, the r-value and p-value on responding to the rapidly transforming academic world, of .295 and .000, consecutively, depicts a positively highly significant result. It clearly shows that the higher the level of adaptability also gives a high teaching performance. It bids to reject the null hypothesis, then. For this finding, it is possible that adaptable teachers are better able to effectively navigate the constant change, novelty, and uncertainty that occur in teaching. This may help them avoid the feelings of helplessness that lead to disengagement. In turn, when teachers put in little effort and have largely "given up", then it's unlikely they would feel an attachment to or personal identification with their job."

\section{CONCLUSIONS}

Going thru a rapid transformation of the Philippine academic world has waved its usual arrangements. Teachers aside from training the students for increasing their skills [21]are being asked to do other related tasks that are somewhat a lot more than the mere teaching responsibilities.It is remarkable indeed, that, studies show that while "arousal increases, performance is enhanced but only up to a certain threshold" [13]. Beyond this threshold, performance will suffer.This study presents the research design, location of the study, respondents of the study, sampling procedure, research instrumentation, and the statistical treatment of the study. Teachers' profile particularly, gender and civil status is not significantly 
related to the performance of a teacher, which, means, that no matter what the gender, male or female may be as productive and effective as they may be. Same with the civil status' effect on teacher's performance that does not directly affect the teacher's performance.On the other hand, Educational Attainment, Area of Specialization, Number of Subject Taught, Number of Teaching Loads, and, Number of Other Related Work, significantly affect teacher's performance for these variables depicts a teacher's productivity. Moreover, the teacher's level of adaptability depicts a good teaching Performance, where, other related tasks as usually located at the end part of the "boxed" teacher's job description, still, teacher's flexibility shines. And when facing "change", no matter what that may be, teachers never give up on innovations, adjustments, and an additional amount of work. They wave flying colors in the field they chose to be in.

\section{REFERENCES}

[1] Altmann E.M. and Trafton, J.G. 2002. "Memory for Goals: an activation based model," Cognitive Science (26:1), pp. 39-83.

[2] Andrew Yap, January 15, 2015, Quote: "Excessive stress leads to mental exhaustion and poor health, but not enough stress results in boredom and demotivation."

[3] Ball, 1990; Fryer, 2016: "In-depth Professional Development"

[4] Baumeister\& Showers, 1986: "Drive Theories"

[5] Baumeister and Showers (1986). "Theories of Choking Under Pressure"

[6] Bedny, G. Z. and Karwowski, W. 2007. A SystemicStructural Theory of Activity: Applications to Human Performance and Work Design. Boca Raton, FL: CRC/Taylor \& Francis. Benbunan

[7] Bedny, G. Z., \& Harris, S. R. 2005."The SystemicStructural Theory of Activity: Applications to the study of human work," Mind, Culture and Activity (12:2), pp. 128 147.

[8] Bedny, G. Z., et.al., 2000."Activity Theory: History, research, and application," Theoretical Issues in Ergonomics Science (1:2), pp. 168-206.

[9] Beilock\& Gray, 2007: "Attentional Theories, Attentional Mechanisms, and Memory Structures"

[10] Calderon (2002) "Three techniques: Descriptive Method of Research"

[11] Chan \&Jarmon, 2004; Markworth, Brobst, Ohana, \& Parker, 2016: "PlanningInstructional Time

[12] Cruel (2010): "Descriptive Research, Describes and Interprets"

[13] Easterbrook, et.al, 1995: "Performance Arousal"

[14] Kendra Cherry, June 24, 2019: "Multitasking"

[15] Matt D'Angelo, 2019:Stanford University study from Clifford Nass Andy Kerns, creative director at Digital Third Coast
[16] Murnane\& Phillips, 1981, Owolabi, 2007, Abraham and Morrison, 2006 and Darling

[17] Hammond, 2000: "Teachers' Years of Experience: A quality Students' Academic Performance"

[18] Robey, D. 2005."Enacting Integrated Information Technology: A Human Agency Perspective," Organization Science (16:1), pp.3-18.

[19] Salvucci and Taagen 2008 "Understanding Multitasking"

[20] Subia, G.S., Amaranto, J.L., Amaranto, J.C., Bustamante, J.Y. and Damaso, I.C. (2019) Chess and Mathematics Performance of College Players: An Exploratory Analysis. Open Access Library Journal, 6: e5195. https://doi.org/10.4236/oalib.1105195

[21] Subia, Gener S. (2018). Think Like My Teacher (TLMT): A New Method in Assessing Millennial Learners. International Journal of Arts, Humanities and Social Sciences.Volume 3. Issue 1.www.ijahss.com. pp. 57-61. 